\title{
INTERRELACIÓN ENTRE VISIÓN EXTERNA Y VISIÓN INTERNA EN LA POESÍA DE JOSÉ ÁNGEL VALENTE
}

Como modelo de acercamiento al universo poético, un enfoque fenoménico se ofrece como medio de estudio idóneo para comprender cuanto los órganos sensoriales son capaces de aprehender y proyectar en el espacio de la creación. Por fenoménico, en este caso, comprendemos, siguiendo la estela de Maurice Merleau-Ponty ${ }^{1}$, un adentramiento mediante la simple percepción en la interioridad completa del mundo, acercándonos de este modo a un espacio donde todo resulte simbólico. El siguiente estudio es una aproximación a la poesía de José Ángel Valente en lo referente a la visión, a la que prestaremos toda nuestra atención, ya que la mirada interior, al margen de aquella otra convencional, mantiene vínculos seculares con la realización poética, además de que constituye un aspecto clave en la obra que nos ocupa. Comprenderemos así, parafraseando a MerleauPonty, el ojo como ventana del alma. Al respecto, Henry Corbin menciona la necesidad de distinguir entre una visión real, "visión testimonial", y "[una] visión del corazón... visión del ojo interior" ${ }^{2}$. En la poesía del gallego es posible observar el paso de una tendencia, llamada a suplantar la mirada externa, por aquella otra dirigida desde y hacia los recovecos del alma. El ojo pasará de ser sujeto de visión a erigirse como portador de visión interna, a erigirse como órgano luminoso donde convergen dos realidades: una física, material, y otra espiritual. Ambas visiones confluyen de lleno en la mirada poética, una mirada que no está

${ }^{1}$ La propuesta fenomenológica del filósofo francés la encontramos en su ya clásica Fenomenología de la percepción, Gallimard, Paris, 1945.

${ }^{2}$ Henry Corbin, La imaginación creadora en el sufismo de Ibn'Arabî, Destino, Barcelona, 1993, p. 269. 
cegada por un pensamiento que interfiere con lo que dicen los sentidos ni, por otra parte, condicionada por todo cuanto la realidad muestra sin la colaboración del entendimiento. El conocimiento sensitivo y el intelectual surgirán a un mismo tiempo, siendo el primero de ellos aprehendido de manera pasiva, mientras que el segundo requerirá de nuestra actividad, de nuestro juicio crítico, con el fin de tornarse en creador de realidades, convirtiéndose así en elemento generador de belleza. Recogemos a continuación una reflexión de Merleau-Ponty que se ajusta a nuestro punto de vista:

Il n'y a pas de vision sans pensée. Mais il ne suffit pas de penser pour voir: la vision est une pensée conditionnée, elle naît "à l'occasion" de ce qui arrive dans le corps, elle est "excitée" à penser par lui. Elle ne choisit ni d'être ou de n'être pas, ni de penser ceci ou cela. Elle doit porter en son coeur cette pesanteur, cette dépendance qui ne peuvent lui advenir par une intrusion de dehors. Tels événements du corps sont "institués de la nature" pour nous donner à voir ceci ou cela. La pensée de la vision fonctionne selon un programme et une loi qu'elle ne s'est pas donnés, elle n'est pas en possession de ses propres prémisses, elle n'est pas pensée toute présente, toute actuelle, il y a en son centre un mystère de passivité3.

El presente acercamiento a la poesía de José Ángel Valente se regirá por afinidades simbólicas más que por un desarrollo cronológico de su obra; si bien, como resulta natural, observaremos cómo muchas de estas identidades evolucionan conforme el autor ahonda, poemario a poemario, en el significado de su cosmos poético. Nos apoyaremos, para lograr este objetivo, en diferentes trabajos cercanos todos ellos a los aspectos aquí tratados. Tomaremos en cuenta las aproximaciones fenomenológicas realizadas por Dionisio Cañas en la década de los años 80, aunque éstas no recogen el último período poético de José Ángel Valente. En Jacques Ancet encontramos estudios sobre la transparencia de la visión, que se centran en el descendimiento del sujeto lírico hacia un espacio germinal, así como en Santiago Daydí Tolson o en Armando López Castro, quienes ahondan en las relaciones entre poesía y silencio, lo mismo que, en el caso del segundo, en la lírica material del gallego. Otros trabajos valio-

3 Maurice Merleau-Ponty, L'Oeil et l'Esprit, Gallimard, Paris, 1964, pp. 51-52. 
sos son los de Eva Valcárcel, en lo relativo a una interpretación de los símbolos en la obra de Valente, o, ya en lo que concierne a las relaciones entre poesía y mística, los de Carlota Caufield y Jorge Machín Lucas. Todos ellos, en su conjunto, ofrecen una interpretación variada en torno a la prioridad, ya del tacto ya de la visión como sentido primordial, desde el que se producirá el salto a lo real, además de que ofrecen diferentes interpretaciones acerca de la naturaleza del espacio abisal alcanzado por José Ángel Valente -teofanía pagana, según considera Machín Lucas, o espacio de asunción de lo divino, según propone María Zambrano. No entraremos nosotros a enjuiciar el sentido último de la poesía del autor, sino que nos conformaremos con seguir la propuesta de Maurice Merleau-Ponty cuando indica que "se trata de describir, no de explicar ni de analizar"4.

Lo que aquí nos proponemos es estudiar las relaciones entre visión interior y visión exterior en el conjunto de la obra del gallego, tratando de atender, en paralelo, a la materialidad con que se manifiesta su lírica. Todo ello, como hemos indicado, desde una perspectiva abarcadora de su obra que nos lleve a comprender esta última como una unidad. Con vistas a esta labor, realizaremos un recorrido que nos lleve, en primer lugar, a observar los límites entre la mirada exterior y la interior, para después entregarnos por medio de esa visión interior a un ámbito de transparencia óptimo para el encuentro de identidades simbólicas. Desde este enclave, ahondaremos en una realidad suprasensible desde la que resulte posible advertir la cercanía entre un plano estético y uno religioso, cuyas estrechas relaciones serán estudiadas en el último de los capítulos que componen el presente trabajo.

\section{LA MIRADA EXTERIOR Y LA MIRADA INTERIOR}

Contemplar invita a la aprehensión de aquella sustancia viva que reside en toda realidad; invita a mirar más allá de lo que los sentidos perciben por sí mismos. Esto requiere de un estado de pasividad, de recepción absoluta de aquello que irradia el objeto de visión y, por otra parte, de un complementario estado de actividad, puesto que la materia pasa a ser observada como

${ }^{4}$ Maurice Merleau-Ponty, Fenomenología de la percepción, Península, Barcelona, 2000, p. 8. 
forma espiritualizada, como forma viviente, simbólica, como representación certera de una voluntad profunda e inaprensible. A ello alude Carlota Caulfield cuando indica que "la poesía es en Valente visión y revelación" , espíritu a la luz del sujeto. Cuanto se perciba resultará sintomático de una realidad capaz de iluminarse mediante relaciones de imágenes, pues "es necesario que las similitudes ocultas se señalen en la superficie de las cosas; es necesaria una marca visible en las analogías invisibles" ${ }^{\prime 6}$, de manera que la realidad misma sea un grado, una posibilidad de acceso a la interioridad del mundo.

Para José Ángel Valente, la mirada contemplativa es la que une el yo racional con el anima, con nuestra naturaleza creadora e intuitiva. El mundo fenoménico podrá conducirnos a esta visión atenta sólo una vez que hayamos dejado de comprenderlo como objeto opaco, carente de interioridad, y comencemos a dotarlo de unidad y transparencia: "Unidad de mirar -indica Valente-: unidad del ser en el ojo o en la mirada única"7. Dado el espesor inicial con que nos presentemos ante la realidad, todo lo que en un primer momento observemos no será sino nuestro propio reflejo, nuestra mirada subjetiva proyectada sobre el mundo, reflejando nuestras carencias, nuestra visión restrictiva de las cosas, enfrentadas unas a otras, no comprendidas como totalidad, sino mediante sus particularidades, alejadas entre sí, puesto que sólo vemos de ellas la superficie, sólo cuanto las diferencia, al margen del nexo común y profundo que las aúna.

La luz, como fuente externa dadora de visión, resulta del todo insuficiente:

La luz..., pero no basta;

no me basta mirar.

Porque empapado está el mirar de sueño,

contagiada la luz por el deseo,

engañados los ojos hasta el blanco

candor de la pupila.

Ojos siempre infantiles,

ávidos de engaño,

5 Carlota Caulfield, Entre el alefy la mandorla: poética, erótica y mística en la obra de José Ángel Valente, tesis, Tulane University, New Orleans, 1992, p. 89.

6 Michel Foucault, Las palabras y las cosas, Siglo XXI, Madrid, 2010, p. 35 .

7 José Ángel Valente, Obras completas. T. 2: Ensayos, Galaxia GutenbergCírculo de Lectores, Barcelona, 2008, p. 315. 
sobornados por cuanto finge el aire, dejadme con el tacto

servil y la certeza simple de lo que toco ${ }^{8}$.

Como vemos, en un primer período, el poeta se apoya en lo sensual, entregándose al contacto con la materia como fuente de conocimiento. La inmersión del poeta en las profundidades posibilita la recuperación de una mirada ingenua, necesaria para la poetización de lo real, que permite así tomar los objetos no sólo como hechos de la materia, sino también como experiencias del espíritu. El ojo debe penetrar, “(El ojo es engañoso) / hasta saber la forma" ", menciona el poeta en las páginas de $P o \ell^{-}$ mas a Lázaro. Es necesario, en este punto, hacer una aclaración acerca del concepto de forma.

Por forma hay que distinguir entre "forma formada" y "forma formante", empleando la terminología propia de Luigi Pareyson $^{10}$, quien indica a propósito de la segunda que:

el artista procede tanteando, sin saber a dónde llegará, pero sus tanteos no son ciegos, sino que están dirigidos por la misma forma que ha de surgir de allí, a través de una anticipación que, más que

8 “La luz no basta”, de Poemas a Lázaro (1960), en José Ángel Valente, Obras completas. T. 1: Poesía y prosa, Galaxia Gutenberg-Círculo de Lectores, Barcelona, 2006, p. 121. (En adelante $O C$ ).

9 “Objeto del poema”, de Poemas a Lázaro (1960), en OC, t. 1, p. 133.

${ }_{10}$ La disyunción entre forma detenida y forma en movimiento nos remite a una oposición elemental desde los presocráticos y estudiada en lo referente a la naturaleza con detenimiento por Spinoza. Pareyson, por su parte, a la hora de comentar uno de los puntos centrales de su estética, indica que "la obra es a la vez la ley y el resultado de su aplicación, forma formata y forma formans al mismo tiempo, presente tanto en los presentimientos del artista como en el producto de su trabajo... La identidad entre forma formata y forma formans no significa solamente que la forma formata realice y desarrolle la forma formans, sino que incluso la forma formans no es otra cosa que la forma formata. El proceso artístico se puede interpretar como la progresiva constatación de tal identidad, en el sentido de que aquél está concluido cuando la obra llega a ser lo que quería ser. Pero desde su inicio no pretende ser otra cosa que aquello que ha de resultar, si resulta. La obra por hacer no es otra cosa que la obra hecha, si se hace y cuando se hace. Esto significa que la necesidad orgánica del proceso artístico es aquella que se proyecta en la intimidad de la libérrima creación del artista: el artista está determinado por su obra, y si no obedece a la coherencia interna de la misma está condenado al fracaso" (Luigi Pareyson, Conversaciones de estética, Visor, Madrid, 1988, pp. 29-30). 
conocimiento, es actividad ejercida por la obra antes incluso de existir... El proceso artístico es, en este sentido, unívoco, como el desarrollo orgánico (p. 92).

Esta explicación, tan confiada en un sentido último de la obra, supone que el artista sólo tiene que seguir los designios del espíritu, de la forma, el camino que ella le impone, con el fin de llevar a cabo su creación, consistiendo ésta, en parte, tal y como indica Valente, en un acto pasivo, de despojamiento de la propia voluntad, de disolución del yo, pero también en un entrelazamiento del espíritu del creador con el de la creación. Pese a todo, no será hasta una época madura de su trayectoria cuando los sentidos logren salir de su propia interioridad para detenerse y tranquilamente asentarse sobre el objeto atisbado.

Uno de los ejemplos más claros sobre el primer período de la obra de Valente, en lo relativo a una visión enfrentada a la realidad, lo encontramos al inicio del poema "No mirar", donde podremos leer versos como:
Escribo lo que veo, aunque podría soñarlo si no tuviera ojos para ver y un reino de ceniza al alcance del viento, si no estuviese en una jaula aprisionado por mis ojos ${ }^{11}$.

El objeto del poema se mantiene ajeno al creador: no se ha producido la mirada interior. Para que ésta acontezca será necesaria una búsqueda de transparencia, una percepción ingenua. Así leeremos:

\footnotetext{
que si de pronto un día recobráramos

la entonación infantil de la mirada caería de un solo golpe el mundo ${ }^{12}$.
}

La caída del mundo equivale a una pérdida de sustancia de la materia en su estado opaco, la posibilidad, por lo tanto, de provocar una comunión de almas y la integración del poeta con el fenómeno sensible, devenido en forma viva de la creación. Se

11 "No mirar", de La memoria y los signos (1966), en $O C$, t. 1, p. 172.

12 "El comité", de El inocente (1970), en OC, t. 1, p. 313. 
produce en esos momentos el "paso de la realidad a lo real", según nos recuerda Jacques Ancet; un estado en el que "las cosas se desvanecen en la luz que las hacía visibles"13. Es entonces cuando la mirada, los sentidos en general, al proyectarse de forma cristalina encuentran en la materia un mundo abierto y carente de límites: "Mirada... ávida, no saciada / (tal estás tú en el estar sumida) / de sólo perdurar, no de esperanza"14. El poema, perteneciente al ciclo Siete representaciones, apunta ya a un estadio al que el creador accederá en momentos puntuales, así como hacia el final de su trayectoria, término que llegará precedido de una sinergia de los elementos que ha conseguido ir liberando.

La transparencia última de la mirada será lo que posibilite al creador permanecer a las puertas del vacío, de un absoluto de signo desconocido: "Desde ese blanco del vacío es desde donde se puede regenerar todo ya que no está adulterado ni por cromatismos artificiales ni por sonidos corrompidos por la falaz historia del hombre" ${ }^{15}$. Se trata, en fin, del punto cero desde el cual la realidad se abre amplia e inmaculada como espacio de reunión del sujeto con el mundo, una vez que se ha accedido a aquel centro no visible y liberado de deseo impositivo.

La materia cumplirá, según vemos, un papel fundamental al momento de acceder a una realidad ulterior; sin embargo, habrá de atravesarse un primer período de rechazo, de furor ante su opacidad, de dureza procedente del propio sujeto, dado que proyecta sobre ella su voluntad, en lugar de atender el fenómeno de modo desprovisto de deseo. Al respecto, Valente comenta que:

la desaparición de una forma en su fana (aniquilación) es el instante de la manifestación de Dios en otra forma... La forma tiende a la aniquilación de cuanto no sea Dios, incluido el acto mismo de aniquilarse ${ }^{16}$.

La forma se convierte así en receptáculo, en templo de la divinidad. La palabra escrita, asimilable a la forma, habrá de desproveerse de sedimentos, llegando entonces a manifestar la ver-

13 JacQues Ancet, "El ver y el no ver: apuntes para una poética", en $E l$ silencio y la escucha. José Ángel Valente, ed. T. Hernández Fernández, CátedraMinisterio de Cultura, Madrid, 1995, p. 154.

14 "IV", de Siete representaciones (1967), en $O C$, t. 1, p. 227.

15 Jorge Machín Lucas, José Ángel Valente y la intertextualidad mística postmoderna, Universidad, Santiago de Compostela, 2010, p. 279.

$16 O C$, t. 2, p. 463. 
dad que permanece escondida en el lenguaje, mostrando éste una doble representación; por una parte, como jaula -armazón necesario, pero molesto-, y, por la otra, como puerta a la realidad, que converge con el elemento vivo que une y anima la materia. Esto último es lo que leemos en el poema "Territorio", perteneciente a Interior con figuras:
Ahora entramos en la penetración, en el reverso incisivo
de cuanto infinitamente se divide.
Entramos en la sombra partida,
en la cópula de la noche
con el dios que revienta en sus entrañas,
en la partición indolora de la célula,
en el revés de la pupila,
en la extremidad terminal de la materia
o en su solo comienzo ${ }^{17}$.

Nada más indicativo, según vemos, que la pupila revertida hacia el interior, pues esto es manifestación de su naturaleza espiritual, que tiende a la contemplación de elementos vivos, acto erótico con el cual se produce la unión espiritual entre los cuerpos. Señala Christine Arkinstall: "En «no mirar» se desmitifica el concepto positivo del poder normalmente atribuido a la vista por una tradición idealista, la cual considera que la imagen, visual y figurativa, proporciona orden a un mundo esencialmente caótico" 18 , siendo ahora precisamente el deseo de bañarse en el elemento caótico, de participar de lleno como fuerza cósmica, lo que invita al sujeto a fundirse en lo más hondo, en lo menos discriminatorio y prejuicioso de la mirada.

Siguiendo con Merleau-Ponty, éste considera como elemental el aprehender la realidad con ojos inocentes con el objetivo de realizar un acto de visión creativa, tal y como lo explica a continuación, tomando como sujeto no al poeta, sino, en este caso, al pintor:

La vision du peintre n'est plus regard sur un dehors, relation "physique-optique" seulement avec le monde. Le monde n'est plus

17 “Territorio", de Interior con figuras (1976), en $O C$, t. 1, p. 339.

18 Christine Arkinstall, El sujeto en el exilio. Un estudio de la obra poética de Francisco Brines, José Ángel Valente y José Manuel Caballero Bonald, Rodopi, Amsterdam-Atlanta, 1993, p. 105. 
devant lui par représentation: c'est plutôt le peintre qui naît dans les choses comme par concentration et venue à soi du vivible, et le tableau finalement ne se rapporte à quoi que ce soit parmi les choses empiriques qu'à condition d'être d'abord "autofiguratif"; il n'est spectacle de quelque chose qu'en étant "spectacle de rien", en crevant la "peau des choses" pour montrer comment les choses se font choses et le monde monde. Apollinaire disait qu'il y a dans un poème des phrases qui ne semblent pas avoir été créés, qui semblent s'être formées. Et Henri Michaux que quelquefois les couleurs de Klee semblent nées lentement sur la toile, émanées d'un fond primordial, "exhalées au bon endroit" comme une patine ou une moisissure. L'art n'est pas construction, artifice, rapport industrieux à un espace et à un monde du dehors. C'est vraiment le "cri inarticulé" dont parle Hermès Trismégiste, "qui semblait la voix la lumière". Et, une fois là, il réveille dans la vision ordinaire des puissances dormantes un secret de préexistence. Quand je vois à travers l'épaisseur de l'eau le carrelage au fond de la piscine, je ne le vois pas malgré l'eau, les reflets, je le vois justement à travers eux, par eux ${ }^{19}$.

La presencia material, en consecuencia, resulta fundamental para adentrarse en la esencia de las cosas, pues puede decirse que sin ella no hay interioridad, en tanto que no es contenida la fuerza creativa. Se rechazará, de este modo, una depuración estéril que tiende a borrar toda huella, toda forma vital. La poesía aglutina, asimila; no rechaza, sino que acepta el mundo y se entrega a él. Fijar los ojos en la rugosidad, en la superficie, detenernos en ella, en cualquier caso, nos impediría alcanzar la profundidad, el espíritu del mundo. Prescindir de estos últimos hondos estratos nos privaría, por lo tanto, de adentrarnos en la voluntad pura: "Tejí la oscura guirnalda de las letras: hice una puerta: para poder cerrar y abrir, como pupila o párpado, los mundos" ${ }^{20}$. El poema, perteneciente a Tres lecciones de tinieblas, reafirma la explicación anterior, esta vez derivada hacia lo referente a la letra. La letra como materia, como forma viva -al menos la escritura hebrea a la que nos remite Valente en este poemario-, actuará a modo de lazo, de conexión entre una realidad primera y otra segunda formada en la abstracción y potenciada por las relaciones simbólicas. Detenernos en su signo, no ir más allá de cuanto se muestra, nos mantendría en el interior de una cárcel, de la jaula donde permanece encerrada nuestra

19 M. Merleau-Ponty, L'Oeil et l'Esprit, pp. 69-70.

20 "Dalet", de Tres lecciones de tinieblas (1980), en OC, t. 1, p. 398. 
conciencia. La palabra nos ha de poner en relación con el mundo, no nos ha de alejar de él, no ha de encerrarnos sin posibilidad de admirar las cosas de modo directo ni a través de formas muertas.

\section{VISIÓN Y TRANSPARENCIA}

El fenómeno físico, la realidad, no deja de situarse entre las coordenadas de lo dionisiaco y de lo apolíneo. La expresión constituye un rasgo del espíritu, no un muro en cuyo seno se oculta éste, y más allá de él aguarda la mirada impotente del esteta. El poeta, en definitiva, deberá ser quien se valga de la forma para alcanzar la totalidad que, entonces, habrá de aparecer como espacio de creación, como lugar donde resulte posible el habitar. Al respecto, Hegel menciona que:

el dios que tiene por elemento de su forma el lenguaje es la obra de arte animada en sí misma, y aquella actividad que antes se contraponía a ella, a la obra que existía como una cosa, resulta que esa obra la tiene ahora inmediatamente en su propia existencia. $\mathrm{O}$ dicho de otra manera (en el lenguaje), es el propio volverse objetivo su ser, la autoconciencia permanece inmediatamente junto a sí misma. Y permaneciendo así junto a sí misma en su propio ser, la autoconciencia es puro pensamiento o pensamiento puro, o fervor y devoción, cuya interioridad cobra a la vez existencia ${ }^{21}$.

En primer lugar, según la aclaración del filósofo, queda claro que el lenguaje no es una segunda realidad, sino un fenómeno primario, proyección directa de la voluntad, presentada de manera tan viva y con tanta pulsión como cualquier otra fuerza elemental. Es más, este lenguaje, como expresión lograda del espíritu, permanece en constante adecuación, en continua transformación, permeando en todo momento la más ínfima modificación de cuanto aviva su sustancia. Se trata, según vemos, de un fenómeno por el que el individuo puede tomar el mundo sensualmente y de manera plena. En segundo lugar, dado que la expresión ha sido entregada al hombre, ésta corre el peligro de sedimentarse, de racionalizarse, tornándose inútil; devendrá entonces en elemento profanado y profanador, en lugar de

21 Georg Wilhelm Friedrich Hegel, Fenomenología del espiritu, PreTextos, Valencia, 2009, p. 812. 
creador de espacios sagrados, en lugar de mostrarse como objeto sagrado, como templo. La forma es o debe ser, como vamos viendo, una concreción de la materia sensible y del pensamiento, convergencia total entre objeto y sujeto; al respecto, Valente menciona: "territorio del poema: no lo visible ni lo invisible, sino el espacio sutil contiguo a ambos (espacio intersticial donde sitúa a Dios el anónimo autor de The clown of unknowing), en el que el símbolo se constituye y los unifica"22. Alcanzamos con este último aspecto el concepto clave de símbolo como elemento de unión entre dos formas aparentemente disociadas.

De acuerdo con Jung, "los símbolos son intentos naturales de reconciliar y reunir opuestos que a menudo están muy separados, como muestra la naturaleza contradictoria de muchos símbolos" ${ }^{23}$. Este origen natural del fenómeno simbólico, esta carencia de intención, es cuanto lo diferencia de la alegoría, cuyo sentido es buscado de manera consciente, permaneciendo aunada a una generalización incapaz de atender al fenómeno individual, a la formación incesante de la materia. La atracción irracional de los elementos habrá que hallarla, por consiguiente, no en cuanto se ha consensuado desde un punto de vista humano, sino en función de aquellos ritmos internos elementales, pulsiones cósmicas de las que participa la creación:

Si los símbolos quieren expresar algo -continúa Jung-, son tendencias que persiguen un fin determinado pero todavía irreconocible y que sólo se pueden expresar mediante analogías... Se tiene a menudo la impresión de que lo inconsciente está intentando penetrar en la conciencia mediante todo tipo de alusiones y analogías, o que lleva a cabo ejercicios preliminares más o menos juguetones para ganar la consciencia para su propia causa ${ }^{24}$.

El símbolo se ofrece, en consecuencia, como el elemento dinámico de la obra, aquel que escapa a las determinaciones de la conciencia y posee la llave, dada su capacidad analógica, para adentrarnos en relaciones de ser más profundas y vivificantes. El símbolo nunca puede resultar obstruido, pues quedaría paralizado el fenómeno estético al quedar neutralizadas las pulsiones derramadas aquí y allá por la creación. En cualquier caso, como

${ }^{22} O C$, t. 2, p. 468.

23 Carl Gustav Jung, La vida simbólica, Trotta, Madrid, 2009, t. 1, p. 248.

24 Carl Gustav Jung, Mysterium coniunctionis, Trotta, Madrid, 2002, pp. $449-450$. 
fuerza viva y atemporal, bastará una mínima abertura para que su potencia surja a la luz del día como espacio de epifanía, buscando siempre, mediante sus metamorfosis infinitas, el modo de unir los elementos disociados. Este constante dinamismo le permitirá ser representado mediante la imagen, pero nunca de modo hierático o alegórico, nunca estático. El símbolo resultará comprensible únicamente a los ojos de quien no se entrometa en su natural dirección, a los ojos de todo creador que, como equilibrista entre fuerzas de generación y de destrucción, aprehenda cada una de las formas sin poseerlas, simplemente ofreciéndolas, expresándolas como don primero de su espíritu, como flor abierta de la creación. Gilbert Durand nos hablará de un:

conocimiento nunca adecuado, nunca "objetivo", ya que jamás alcanza un objeto, y que siempre se pretende esencial, ya que se basta a sí mismo y lleva en su interior, escandalosamente, el mensaje, inmanente de una trascendencia; nunca explícito, sino siempre ambiguo y a menudo redundante ${ }^{25}$.

El símbolo aproxima, como vamos viendo, un absoluto, sin mostrar explícitamente su procedencia o su fin, pues de poseer un inicio o un final los desconocerá. En cambio, sí que mostrará una trayectoria en función de la cual el poeta mismo o el lector tendrán que sospechar un elemento ausente que quizás se esconda detrás. Durand menciona al respecto que "al no poder representar la irrepresentable trascendencia, la imagen simbólica es transfiguración de una representación concreta en un sentido totalmente abstracto. El símbolo es, pues, una representación que hace aparecer un sentido secreto; es la epifanía de un misterio" 26 velado, pero observable de modo indirecto.

El territorio donde habita el poeta se situará allí donde se encuentre el fenómeno viviente, donde habite la fuerza impalpable, pero segura que guía las manifestaciones, allí donde surja la necesidad de expresión de un elemento ya formado, sabiendo, sin embargo, que todo lo que nos ofrece continúa impasible su tránsito y por ello mismo deberá, en ocasiones, reflejar no sólo su formación, sino su deformación, fenómeno incomprensible en su trayectoria completa para nuestro obtuso entendimiento, puesto que no se presentará de forma desarrollada y lineal:

25 Gilbert Durand, La imaginación simbólica, Amorrortu, Madrid, 2007, p. 21.

${ }^{26}$ Ibid., p. 15. 
El asombro filosófico y el asombro poético convergen en su destino último de proporcionar conocimiento, aunque sus procedimientos naturales son divergentes. El primero, el asombro filosófico, requiere un movimiento que va desde el pasmo mismo hasta la violencia de la persecución de una respuesta recóndita que se oculta y que, en ningún momento, se nos ofrece sin resistencia. La perplejidad poética, por el contrario, se entrega como una gracia ofrecida, se manifiesta sorpresivamente sin apenas búsqueda, siempre que se den las condiciones justas para el vuelo ${ }^{27}$.

La transparencia será, según vemos, necesaria, dada la demanda del poeta de ir siempre más allá, de avanzar al mismo ritmo que su voluntad, sin restricciones, sin frenos, permitiéndole mostrarse como sujeto completamente dinámico:
¿Cómo podría adentrarme más en este otoño, cómo podría a lo menos visible entrar desde los oros de tu feraz recogimiento, madre naturaleza? ${ }^{28}$

Sin duda alguna, los sentidos constituyen un elemento de adecuación, pero, a su vez, son también un necesario elemento de restricción, en tanto que el poeta buscará la expresión y, por lo tanto, no sólo la transparencia, sino también la formalización. La eclosión de dos miradas, de dos cuerpos, posibilitará la percepción de ritmos, de elementos palpables que hacen consciente la creación, propiciando su feliz emergencia sobre la superficie.

\section{LA VISIÓN LÍRICA}

Dentro de Material memoria, en una reflexión en torno a la pintura de Tàpies, podemos leer una aclaración que resulta válida en lo referente al criterio de búsqueda emprendido por el poeta al aludir a un:

estado en que la experiencia se configura ante todo como experiencia de la unificación. El arte de Tàpies es, en definitiva, una

27 Eva Valcárcel López, "Variaciones sobre el pájaro y la red. El deseo y el verbo. El poeta y el místico. Reflexión sobre dos experiencias extremas", en Material Valente, ed. C. Rodríguez Fer, Júcar, Madrid-Gijón, 1994, p. 277.

28 "Declinación de la luz", de Interior con figuras (1976), en OC, t. 1, p. 368. 
soberana contemplación de la materia. Presencia radical de la materia que llega a la forma, pero que es sobre todo formación: formas que se disuelven a sí mismas en la nostalgia originaria de lo informe, de lo que en rigor es indiferente al cambio y puede, por tanto, cambiarse en todo, ser raíz infinita de todas las formas posibles $^{29}$.

El ahondamiento en lo real se posibilitará una vez dejado al margen cualquier concepto previo que desvíe de la esencia de lo indagado. El grado de descendimiento a la raíz, a la materia, es tan extremo que se prescindirá de toda solidez, ya sea de orden intelectual ya sensitivo, siendo esta "visión del arte como materia interior" 30 , el aspecto donde, según Armando López Castro, confluyen la estética de Valente y la de Tàpies. Este descenso a un espacio germinal de la obra nos presenta el fenómeno poético como un hecho natural más, manifestación completa, divinización lunar, entrega absoluta entre lo expresado y un reino dominado por las aguas, por la germinación y la disolución de la palabra, "entrada radical en la materia... sentir, en definitiva, la respiración o neuma de la materia" 31 , permitiendo así que la voz se enriquezca con elementos que no pertenecen ya al reino de las formas formadas, sino al de la vida creativa.

A partir de este período de inmersión profunda, José Ángel Valente se centra en la contemplación del dios, en la superación de toda forma saturada de sentido, de toda coagulación, de modo que la mirada del poeta se irá perdiendo en la noche oscura, en la nada, en el ojo de Dios, vaso comunicante entre su yo consciente y su alma. La transición es, en definitiva, la de lo humano a lo divino. Se rechazará todo juicio, pasando de ser el poeta la figura que contempla a ser el observado por el ani$m a$, por su ojo espiritual, por el órgano que le une de lleno con lo más cierto y vivo de la creación: "poso en fin ante nadie o ante nada / o ante la pupila transparente / que nunca veo y que me ve"32, una visión, "una luz, que curiosamente, no viene del cielo, sino del agua... un agua primordial, lumínica, un agua

29 “III", de Material memoria (1979), en OC, t. 1, p. 388.

30 Armando López Castro, "Tàpies y Valente: hacia una visión de la materia interiorizada”, en José Ángel Valente, ed. C. Rodríguez Fer, Taurus, Madrid, 1992, p. 295.

31 "IV", de Material memoria (1979), en $O C$, t. 1, p. 389.

32 "Umbral", de Mandorla (1982), en $O C$, t. 1, p. 418. 
portadora de luz" ${ }^{33}$. Esta luz procedente de las aguas coincide con la ya mencionada luz interior, luz del alma que viene a sustituir a aquella otra creadora de sombras, no pura, de la que participa nuestro poeta en etapas anteriores de su obra, tal y como leemos en los siguientes versos de El inocente. "qué oscuro el borde de la luz / donde ya nada / reaparece"34. La mirada-que para María Zambrano es la función principal del conocer en la poesía de Valente ${ }^{35}$ - será, en su poesía madura, la proyección de alma a alma entre sujeto y objeto, fenómeno consustancial al de la acción poética. Esta última, para Valente, según relata Lacalle Ciordia, "es una visión corpórea de la espiritualización del cuerpo... Este cuerpo suspendido y transparente encarnará su entera materia cósmica interiorizada y desconocida" 36 , con la cual converge la mirada tomando parte, sin poseerla, del ritmo interno que la aviva.

La confluencia entre la mirada divina y la humana a la que asistimos no es sino un lazo, un acercamiento entre lo eterno y lo temporal, entre el poeta y la voz que canta desde su interior. En palabras de Merleau-Ponty: "La vision est la rencontre, comme à un carrefour, de tous les aspects de l'Être... Dans ce circuit, nulle rupture, impossible de dire qu'ici finit la nature et commence l'homme ou l'expression" ${ }^{37}$. Este acto de mirar consiste, paradójicamente, en un despojamiento del mirar, en la sustitución de unos sentidos comprendidos como puertas hacia fuera por aquellos otros que permiten el encuentro; en fin, en la permeabilidad de lo hasta entonces extraño, en un reencuentro con la naturaleza perdida en el laberinto de nuestro entendimiento. "El desnudo volvió solar el día" 38 , indica el autor en alusión a una desnudez entendida como desprendimiento de juicio, como la transformación del sujeto en órgano puramente receptor. El sol que recibimos no será tanto aquel procedente de las alturas como el que surja del interior del creador, de la palabra, trans-

33 OC, t. 2, p. 479.

34 "Límite", de El inocente (1970), en $O C$, t. 1, p. 318.

35 La comprensión que María Zambrano tiene de la visión como sentido primordial en la obra de Valente puede leerse en su artículo "La mirada originaria en la obra de José Ángel Valente”, en José Ángel Valente, ed. C. Rodríguez Fer.

36 M. Ángeles Lacalle Ciordia, José Ángel Valente: la palabra, lugar de encuentro, Ayuntamiento, Tudela, 1998, p. 73.

37 M. Merleau-Ponty, L'Oeil et l'Esprit, pp. 86-87.

38 "Desnudo", de Mandorla (1982), en OC, t. 1, p. 409. 
parente ya, órgano de visión y ventana hacia el mundo externo. Henry Corbin explica este desarrollo del siguiente modo:

la visión imaginativa testimonial... se hace visión del corazón..., es decir, visión del ojo interior..., que es la visión de Dios por sí mismo, siendo el corazón el órgano, el "ojo" por el que Dios se ve a sí mismo: el contemplador es lo contemplado (la visión que yo tengo de él es la visión que él tiene de mí $)^{39}$.

Asistimos en todo ello a un proceso de ablución si partimos de la base de que no sólo los conceptos surgidos en nuestro entendimiento han quedado corrompidos, sino que, dada la relación total de intimidad entre pensamiento y sensibilidad, resulta necesario reeducar las percepciones, despojarlas del lastre que un exceso de voluntad y de narcisismo les imponen, impidiéndonos salir al contacto con la realidad, con un mundo exterior que nos espera. Esta realidad, una vez franqueada la barrera levantada por nosotros mismos, no nos devolverá cuanto proyectamos desde la conciencia, sino que, abierta nuestra capacidad perceptiva -en este caso nuestra visión-a nuestro espíritu, nos permitirá ser capaces de interrelacionarnos con el exterior de modo sano, no impositivo, enriqueciendo nuestra vida al permitirnos moldear nuestra sensibilidad con todo lo que nos llega desde el exterior. En este punto, el arte, el fenómeno estético, se entiende como actividad educadora del espíritu, como modelo de realización personal. El arte será fuente de proyección hacia el exterior y hacia el interior, quedando modelado el mundo en función de nuestro yo, y siendo moldeado, a su vez, este último por el mundo fenoménico.

\section{LA IMAGEN COMO ALEJAMIENTO DEL MUNDO}

El proceso que venimos estudiando, dirigido, dada la naturaleza excéntrica de Valente, hacia lo absoluto, conllevará en último término el rechazo de toda imagen creada por el hombre, al ser tratada ésta como plasmación sensible de la nada, empleando la terminología propia de la mística negativa tan grata al poeta, necesariamente inexpresable. La imagen no unirá, sino que separará en aquellos momentos en que lleve asimilada una carga concreta, definida. Veamos el poema siguiente:

39 H. Corbin, op. cit., p. 269. 
El filo: todo lo que nos separa

de nuestra propia imagen

que desde los espejos

nos mira y no nos ve.

Perfil borrado.

No

adorarás imágenes ${ }^{40}$.

El fenómeno religioso quedará sorprendentemente arraigado en la experiencia estética desprovista de un componente moral. Comenta Daisetzu T. Suzuki:

Los impulsos artísticos son más primitivos y más innatos que los morales. La llamada del arte apela más directamente al interior de la naturaleza humana. La moral es reguladora, el arte es creador. Aquélla es una imposición del exterior, éste es una irrefrenable expresión del interior ${ }^{41}$.

La intención del poeta será realizar, empleando sus propios términos, un acto de retracción:

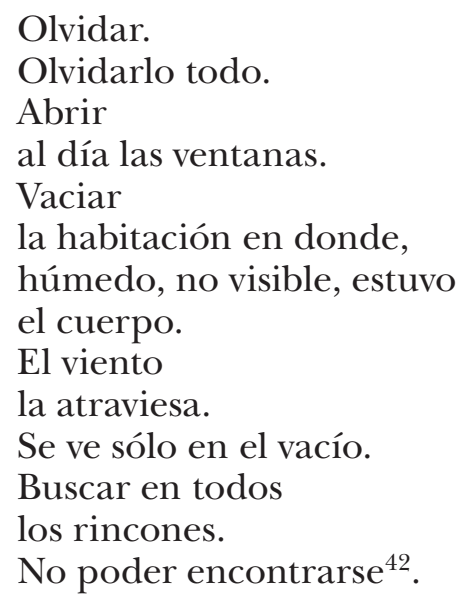

Este atravesar se manifestará como la cohabitación de Dios en el hombre, toda vez que éste se presente como catalizador entre espacios divinos, entre fuerzas vivas, resultando de ello la convergencia absoluta de la creación en su propio ser, con-

40 "Yom Kippur", de Mandorla (1982), en OC, t. 1, p. 420.

41 Daisetzu T. Suzuki, Budismo zen, Kairós, Capellades, 2003, p. 88.

42 "II", de El fulgor (1984), en $O C$, t. 1, p. 444. 
vertido, como vamos viendo, en lugar de encuentro, en templo sagrado de la creación. En este aspecto, resultan indicativas las palabras de Shizuteru Ueda que remiten a que:

El "atravesar" es el retorno del alma más allá de Dios, hacia el fondo de Dios... La "deidad", de la que Eckhart habla propiamente como diferente de Dios, es el "fondo" de Dios, del cual deviene y en el cual deja de ser; de hecho, deja de ser cuando el alma retorna, atravesándolo, al fondo de dios ${ }^{43}$.

Esta última noción en Valente quedará reducida a un ocultamiento del sujeto consciente, de modo que la naturaleza creativa, viva, confluya con la creación. De acuerdo con el poeta:

El creador tiene que ir acostumbrándose a la aniquilación del "yo" que es el proceso de purificación espiritual. Toda creación literaria auténtica, poética, por utilizar la palabra poética en su sentido más amplio, tiene que ir acompañada de una experiencia espiritual, si no, no vale de nada. Eso lleva a una aniquilación del "yo" y probablemente a una visión de la nada, aunque positiva ${ }^{44}$.

Sin identificar de qué se trata, la nada queda al momento desvinculada de toda comprensión oscura y nihilista.

Las anteriores declaraciones nos guían hacia una poesía con hondas raíces místicas, lo que supone, desde luego, poner en tela de juicio la validez de los sentidos. La lucha con la materia es necesaria, pues en último término llevará al desinterés por el propio yo como sujeto poseedor de personalidad. Será en la retirada del ser donde la creación suplante al creador y logre así ahondar más de lo que la sola voluntad individual sería capaz de llevar a cabo. Una vez despojado el sujeto de la carga consustancial al yo, desprovisto del conjunto de dogmas a partir de los cuales es sustituida la verdad por el prejuicio, resultará posible el acercamiento a la realidad como templo, a la divinidad por medio de los sentidos, a esa visión de la nada positiva a la que aludirá el poeta tal y como la encontraremos en el siguiente poema: "AL CAER la tarde, la no visible mano de un dios te borra como ala de pájaro caído hacia qué densa sombra más allá de la

43 Shizuteru Ueda, Zen y filosofía, Herder, Barcelona, 2005, pp. 71-72.

44 José Ángel Valente y Nuria Fernández Quesada (eds.), Anatomía de la palabra, Pre-Textos, Madrid, 2000, p. 147. 
sombra. Disuelto estás, al fin, en tu propia mirada"45. La unión resulta completa, ya que es una reunión del alma a través de los cuerpos.

En cualquier caso, según indica Valente, la obra de arte no es toda ella su cuerpo en la medida en que lo expresado no agota todo cuanto se quiere significar. Quedará alrededor de ella un remanente no dicho, no expresable, que será aquello que la torne absolutamente simbólica, aquello que la haga sobrepasar el contenido exacto de lo dicho para reverberar en lo que ha quedado fuera del acercamiento sensorial. Santiago Daydí-Tolson, a la hora de comprender este aspecto, alude a ciertas "técnicas de resonancia" que se entienden como "diversos procedimientos expresivos que, aunque difieren bastante entre sí, comparten al menos una característica común: la capacidad de suscitar ecos y correspondencias múltiples dentro del texto literario mismo, o entre éste y sus varios posibles contextos" ${ }^{36}$. El crítico continúa indicando que:

los efectos de resonancia se producen en tres planos de la estructuración del poema: el de la representación anecdótica, el de las imágenes (o del léxico), y el acústico-rítmico... todos tienen en común el establecer relaciones y sugerir correspondencias entre elementos textuales, o entre éstos y otros del contexto cultural y lingüístico común al poeta y sus lectores. Todo caso de resonancia produce una armónica correlación entre varios elementos que se complementan y enriquecen unos a otros en la síntesis de su captación ${ }^{47}$.

El aspecto que nos interesa de esta triple división de los efectos de resonancia empleados por Valente es la remisión a un orden acústico-rítmico, en tanto que, sobrepasando la representación, este orden se muestra especialmente proclive a aunar la voluntad de generación poética con el espacio vacío hacia el que tiende la naturaleza mística de la creación. Según Mircea Eliade -pudiendo aplicarse su definición a la experiencia poética-, "queda un fondo irreductible, incomunicable, para mayor p. 499.

45 “AL CAER la tarde...", de No amanece el cantor (1992), en $O C$, t. 1,

46 Santiago Daydí-Tolson, "Los efectos de la resonancia en la poesía de José Ángel Valente", The analysis of literary texts. Current trends in methodology, Bilingual Press, Ypsilanti, 1980, p. 280.

47 En José Ángel Valente, ed. C. Rodríguez Fer, p. 283. 
precisión, aquello que es imposible de expresar o comunicar, y es ese fondo misterioso, incalculable, lo que «pasa al más allá» y sobrevive a la desaparición del cuerpo" 48 . Esta separación, por lo tanto, entre lo que se percibe y aquello que se quiere designar, queda medianamente superada gracias al eco, gracias a la reverberación que aproxima sin jamás llegar.

\section{ILUMINACIÓN DEL COSMOS POÉTICO}

En la obra de Valente, cabe observar, en otro orden de cosas, el choque de la voz con un universo de formas que hace restallar una serie de elementos periféricos por medio de los cuales resulta posible conocer las intenciones últimas del autor, así como comprender su deseo de ir más allá de cuanto se ha podido o deseado manifestar. Puede así decirse que, en ocasiones, queda más claramente expuesta la meta de alcanzarse no mediante el acercamiento hacia esa misma meta, sino mediante la observación de los restos poéticos que el sujeto lírico va dejando a su paso a medida que ha ido derribando una serie de obstáculos intermedios, en los que las palabras y los fragmentos se han presentado como manifestación de la dirección tomada por la voz del poeta. En el poemario Al dios del lugar, encontramos una muestra de ello en los siguientes versos:

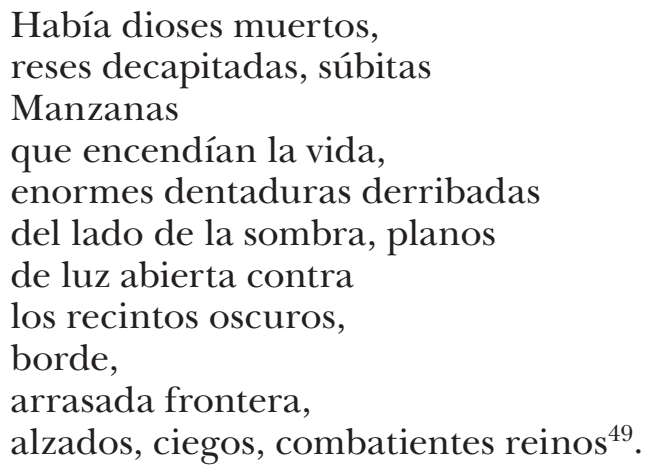

Lo esparcido por el espacio iluminado es una serie de restos, de fragmentos abandonados al paso de un verbo en camino

48 Mircea Eliade, El vuelo mágico, Siruela, Madrid, 2005, p. 227. p. 474.

\footnotetext{
"HABÍA dioses muertos...", de Al dios del lugar (1989), en $O C$, t. 1,
} 
hacia una divinidad de la que se ha perdido todo rastro, quedando sólo los destrozos que, a su paso, la voz ha dejado como símbolo innegable de su progresión ascendente hacia un orden superior. Aquello que podremos observar, por lo tanto, no será ya el objeto a designar, sino las huellas de la palabra a su paso.

Los sentidos, la visión en concreto, como vamos viendo, aportarán un índice, un principio de materialidad sobre el que apoyarse para, a partir de ellos, elevar nuestra mirada hacia el mundo del espíritu. El ojo asciende, "secreto y súbito y continuo: el ojo, / como un extraño globo, sube hacia lo infinito" ${ }^{50}$. De este modo, la mirada se amplía, captando de manera más unitaria el mundo de objetos que podemos ir observando. Cuanto tomemos mediante nuestros sentidos debe, no obstante, participar de una operación más con el fin de captar todo el contenido de aquello que se nos presenta. Esta operación, anticipada líneas atrás, consiste en el establecimiento de una serie de identidades simbólicas que, a modo de vibraciones, expandirán la onda de imágenes poniendo en relación lo manifestado con lo apenas ya expresable, último paso antes de entrar en un terreno sagrado en ámbitos ya más lejanos de lo que la realización artística puede llegar a alcanzar. Santiago Daydí-Tolson señala: "El color... es un accidente de la luz, en cierto modo una deficiencia de la misma"51, en la medida en que encubre esa visión absoluta, no ver, tan buscada por el poeta en un período maduro de su trayectoria. Al respecto, el propio José Ángel Valente señala que:

la palabra poética sólo se cumple o se sustancia en ese borde extremo del silencio último que ella integra y en el que ella se disuelve. No tiene esa palabra más territorio propio que el descrito en esa bellísima expresión de Hallaŷ: "Los desiertos de la proximidad". Palabra, pues, del límite, del borde o de la inmanencia, la palabra poética no es propiamente el lugar de un decir, sino de un aparecer. El poema, al igual que el Señor del Oráculo, no dice, no afirma ni niega, sino que hace signos; significa, pues, lo indecible, no porque lo diga, sino porque lo indecible en cuanto tal aparece o se muestra en el poema, lugar o centro o punto instantáneo de la manifestación ${ }^{52}$.

50 "Odilon Redon", de Interior con figuras (1976), en $O C$, t. 1, p. 342.

51 S. DAy dí-Tolson, "Las sombras y la luz: representación visual en la obra de José Ángel Valente”, en Material Valente, ed. C. Rodríguez Fer, p. 37. ${ }^{52} O C$, t. 2, p. 423. 
El poema es centro, anclaje alrededor del cual van a ir apareciendo significados que no se mencionan explícitamente, pero sí simbólicamente. El acercamiento al verbo, su aprehensión, no agotará su decir, algo que resulta, incluso, conveniente, de cara a tomar toda su sustancia, merodear en torno a él sin ceñirse por completo a su núcleo, fuente primera de reverberación. El poema, la oración, necesita de grietas que le permitan exudar, que le faciliten respirar, que posibiliten, en fin, su relación con el mundo exterior y que no constriñan sus matices mediante la exacta comprensión de lo dicho.

Dado el universo de símbolos por el que nos adentramos, la visión -y esto también se puede extender al resto de las proyecciones sensoriales-, por mucho que se detenga en un solo objeto, en un solo contorno, aprehenderá mucho más de lo expresado por esa escueta forma, pues ésta se encuentra saturada de contenidos que, además, varían su significación, según se perciban desde una u otra perspectiva, siendo así, como ya hemos señalado, que toda forma viva posee una radiación. No observamos, por lo tanto, en la poesía de Valente, dada su notable carga espiritual, univocidad, sino confluencia de sentidos, donde es más importante el acto de ver -no como dinámica unidireccionalque el objeto visto. Así, leemos en No amanece el cantor: "VEO, veo. Y tú ¿qué ves? No veo. ¿De qué color? No veo. El problema no es lo que se ve, sino el ver mismo. La mirada, no el ojo. Antepupila. El no color, no el color. No ver. La transparencia"53. Podemos decir que lo alcanzado exclusivamente de manera sensorial será una obstrucción para la visión profunda, pues no alcanzará a presentir la esencia del objeto, inaprensible en la medida en que, siguiendo a Goethe, podría decirse que ese objeto no es únicamente cuanto muestra, sino toda una serie de correspondencias de las que forma parte y sin las cuales no podría existir. Así, el ser cobrará vida dentro de una rueda cósmica de inagotable espectro, alcanzándose a captar de este último únicamente lo que el sujeto ya posee en su interior.

\section{Adentramiento en la totalidad}

En el centro de esta cadena de correspondencias que vamos comentando se sitúa la nada, el ojo divino transparente, los tres

53 “VEO, veo...", de No amanece el cantor (1992), en OC, t. 1, p. 492. 
ojos de Shiva, ajenos al instante comprendido como unidad segmentada, pues con ellos se abarca la totalidad. En el poema "De amigo", perteneciente a Cantigas de alén, el poeta menciona: "Ahora / ante nosotros / la nada surge última / como todo origen" 54 . Atravesar todo el espectro de elementos intermedios que reúnen el origen con el fin nos remitiría de nuevo a una unidad entendida como completitud, comprendida como, siguiendo a Plotino, el Uno divino que contiene en sí toda la cadena del ser. Estudioso del Tao y, por lo tanto, cercano a Valente en no pocos aspectos, François Cheng menciona que "una obra que alcanza la grandeza contiene una infinidad de intenciones y de virtualidades; es verdaderamente la figura del infinito en lo finito, único lugar en que las contradicciones se resuelven en paz" ${ }^{55}$. La visión surge como elemento de apoyo a partir del cual se levantan velos denotativos de una unidad superior de naturaleza inaprensible. En el fenómeno en sí, de acuerdo con el pensamiento del poeta, no se puede observar directamente la imagen numinosa, pero sí se puede lograr un acercamiento a ella por analogía, estando aquélla presente en cada una de las manifestaciones observadas $\mathrm{y}$, si se quiere, en ninguna, pues las representaciones participan, pero no son idénticas a la voluntad creadora.

Con la expresión poética ocurre exactamente lo mismo, de ello resulta la necesidad de ahondar simbólicamente en la palabra individual con el propósito de establecer relaciones armónicas que enlacen imágenes distantes y así, de este modo, dotar de sentido al conjunto de elementos que permanecen a ambos extremos de la creación. Un ejemplo lo observamos en "LA VERDINEGRA / ascensión amarilla de la piedra / sobre el fondo oscuro, solitario, del aire" ${ }^{56}$, tomado de Fragmentos de un libro futuro. Es usual en la poesía de Valente encontrarnos con una serie de concatenaciones que rodean el objeto central, el núcleo del poema, sin llegar a designarlo. Pese a ello, ese centro resulta más visible, sus contornos más claros que si se hubiesen señalado de modo directo. El núcleo del poema quedará aparentemente vacío; de él sólo percibiremos el cerco formal que le confiere la cualidad de espacio, aun cuando de éste no conozcamos su interioridad. Esa delimitación, por su parte, es más significativa

54 "De amigo", de Cantigas de alén (1996), en $O C$, t. 1, p. 524.

55 François Cheng, Cinco meditaciones sobre la belleza, Siruela, Madrid, 2007 , p. 86.

56 "LA VERDINEGRA...", de Fragmentos de un libro futuro (2000), en $O C$, t. 1 , p. 569. 
que cualquier otra manifestación al descondicionar un centro que, de otro modo, perdería su condición de sagrado. Por todo ello, podremos ver el límite del objeto y, de este modo, observar de él tan sólo su ausencia, su transparencia, la cual ejercerá una atracción singular que, al no quedar su interior reflejado sobre el poema, invitará a explorar el sentido último de ese silencio para así dotar de significado completo a la totalidad.

Esta nada central es el tema del siguiente poema que fue tomado del ya mencionado Fragmentos de un libro futuro:

\author{
ESTÁS \\ en tu luz no visible, no engendrado, \\ único, el único. \\ Se posa tu mirada \\ en la ausencia de ti o en la no descifrable \\ irrupción de tu forma en tu vacío. \\ Y allí dejas la huella de tu paso. \\ Salí tras ti. \\ Devuélveme a tus ojos \\ que llevo en mis entrañas dibujados ${ }^{57}$.
}

Este último verso, un guiño a san Juan de la Cruz ${ }^{58}$, de nuevo relaciona la visión humana con la divina, la convergencia sujeto-objeto, en cuanto que el despojamiento del velo de la representación posibilita la emanación de la luz interior que aúna la percepción con lo fenoménico. En este aspecto, según refiere Robert Langbaum:

el significado reside en nuestra conciencia del "poder sintético y mágico” del poeta, en nuestra percepción de la presencia del poeta en el poema. Los elementos en conflicto existen sólo para ser reconciliados, como signos del poder conciliador del poeta ${ }^{59}$.

57 “ESTÁS...", de Fragmentos de un libro futuro (2000), en $O C$, t. 1, p. 571.

58 Resulta interesante observar cómo aquello que se presenta en el abulense de modo nítido, en el poeta gallego se muestra oscurecido, indescifrable. Al respecto, cabe recordar la estrofa completa presentada por san Juan en su Cántico espiritual: "¡Oh cristalina fuente, / si en esos tus semblantes plateados / formaste de repente / los ojos deseados / que tengo en mis entrañas dibujados!" (Poesía completa y comentarios en prosa, Planeta, Barcelona, 2002, p. 7).

59 Robert Langbaum, La poesía de la experiencia, Comares, Granada, 1996, pp. 370-371. 
Por ello, puede concluirse que una aprehensión sensorial manifiesta la variedad que, posteriormente, una vez interiorizada, desvela una unidad atisbada o, incluso, interiorizada en el momento en que la transparencia del entendimiento del poeta le permite hacerse todo él ojo, visión, al grado de identificar su mirada con la del universo creador:

\author{
TU SÚBITA presencia. \\ Toda tu luz irrumpe duradera, dura \\ como la piedra. \\ Vienes \\ tan inmóvil, tan adentro de ti. \\ Lo hondo. \\ En tu sola existencia, \\ tu sola luz, estás \\ ardiendo para siempre ${ }^{60}$.
}

La visión de la que participa el poeta no será ya aquélla propiamente personal, sino la que le ofrece la divinidad. El creador podrá ver, entonces, la realidad con ojos transparentes, no sujeto a prejuicio alguno, permitiéndose el libre paso hacia un mundo como ámbito de orden divino, pues "en la medida en que la palabra se libera de sus ídolos, se aproxima a la dimensión perdida de lo sacro" ${ }^{61}$. Una vez logrado el acercamiento al mundo desde lo no profano, y habiendo adquirido una visión interna, espiritual, de lo real, "se produce entonces una inversión de perspectiva. Mientras el hombre se convierte en el interior del paisaje, éste se convierte en el paisaje interior del hombre"62. El espíritu del poeta logrará aunar cuanto la realidad palpable nos muestra desmembrado, "porque en verdad el viaje iniciado por Valente es similar al del místico -señala Dionisio Cañas-, y su aspiración última es la búsqueda de esa noche oscura a través de la cual, vaciada incluso la escritura de su contenido, una oquedad, una nada, un vacío, permitirían el verdadero nacimiento de algo más trascendental" ${ }^{3}$. La conexión simbólica será entonces absoluta, no debiendo el poeta sino estar atento a los fenómenos

\footnotetext{
$O C$, t. 1, p. 568.

61 Armando López Castro, "José Ángel Valente: memoria del verbo", CuLH, 1995, núm. 20, p. 125.

${ }^{62}$ F. Cheng, op. cit., p. 69.

63 Dionisio Cañas, "La mirada nocturna: José Ángel Valente", en Poesía y percepción, Hiperión, Madrid, 1984, p. 187.
}

60 "TU SÚBITA presencia...", de Fragmentos de un libro futuro (2000), en 
reunidos por afinidades internas, por aquellos ritmos que Marius Schneider consideraba previos a la manifestación, al acto de ver o al habla poética.

La poesía de Valente, como vamos observando, parte de un primer estadio de comprensión de la realidad como materia, como muro opaco donde toda luz procede del exterior, en el que el poeta tiene cerrado el paso al elemento simbólico latente en el seno de esa realidad. A continuación, le sigue un período posterior de búsqueda de transparencia, ocurrido una vez que el creador echa por tierra sus dogmas, permitiendo el disfrute de lo sensible y la comprensión de su presencia como modo de acercamiento, de contacto pleno con la realidad. Por último, acaecerá un adentrarse en el objeto por medio de relaciones simbólicas profundas que muestren la armonía hasta ese momento oculta e imperceptible para los órganos de conocimiento. Al respecto, traemos a colación unas palabras de Juan Eduardo Cirlot que se adecuan perfectamente al proceso llevado a cabo en la poesía de Valente:

El espíritu penetrante, el hombre como mensajero del ser, en su actividad y propagación puede sentir la oposición del mundo en uno de estos tres aspectos: como cerrada imposibilidad de avance (agnosticismo, sentimiento de Caverna, de Frobenius) ${ }^{64}$; como abertura y libertad gozosa (activismo, sentimiento de Lontananza, del mencionado antropólogo) o como reflejo de sí mismo, y respuesta (religión deísta); podríamos especificar simbólicamente estas tres "situaciones esenciales" en los objetos correlativos: pared, ventana, espejo ${ }^{65}$.

El poema, de este último modo, pasa a ser sujeto y objeto a un mismo tiempo, devolviendo la mirada proyectada por el autor, libre ya de imposturas. Por consiguiente, lo creado no absorbe, sino que refleja el mundo, de ello resulta su validez en todo

${ }^{64}$ El mismo Juan Eduardo Cirlot, en su Diccionario de símbolos (Siruela, Madrid, 2011, p. 165) indica que "la cueva, o caverna, tiene en Platón un sentido... en el fondo menos simbólico que alegórico, como representación del mundo fenoménico, mientras su exterior, realidad luminosa y abierta, expresa el mundo de las ideas. Probablemente, en esta transformación de sentido vería Frobenius (que habló de dos sentimientos del mundo: de libertad y de caverna) un paso del orden que da prioridad a la naturaleza, a la mujer, a la materia, al que da la preeminencia al espíritu y al padre".

65 J.E. Cirlot, El ojo en la mitología. Su simbolismo, Huerga y Fierro, Madrid, 1998, p. 72. 
tiempo y lugar. Muy indicativa es la breve alusión que, de este aspecto, realiza Victoria Cirlot ${ }^{66}$ cuando indica que "el objeto de la visión es lo que se ha introducido dentro de la mandorla". $\mathrm{Si}$ acudimos al poemario homónimo de Valente, observaremos cómo, efectivamente, en el interior de la mandorla permanece la luz, identificable con el centro, con el verbo: "Durar, como la noche dura, / como la noche es sólo sumergido cuerpo / de tu visible luz" ${ }^{67}$. Valga recordar, en este punto, y aun de pasada, la relación de identificación, no sólo en este poema, sino en el ámbito de la simbología como ciencia, entre el ojo y el sexo femenino ${ }^{68}$, ambos elementos están relacionados con la generación, así como con la representación de multitud de mitos solares. Aludimos, obviamente, no al ojo humano como tal, sino al anímico, al divino.

Cuanto se persigue, para acabar con esta cuestión relativa a la visión del poeta, no dejará de ser una comunión de cuerpos, un liberar la "fluidez del universo y dar a la palabra la disponibilidad de la manifestación, la faz del espejo que vuelve una y otra vez a ser expectativa libre de una imagen posible"69. El espejo precederá, en última instancia, a la visión pura, de alma a alma, al acercamiento más allá de los cuerpos, opción a la que se aboca el poeta ya en sus últimos versos. La sombra planea sobre la carne, el poema habla de unas "pupilas ciegas" ${ }^{70}$ necesitadas de luz, necesitadas de esperanza, desde donde el creador espera adentrarse "en los oscuros pliegues de la noche"71. El poeta comenzará, entonces, a arder entre tanta sombra, desvaneciéndose con luz propia su cuerpo, pues converge ya con la voz que sigue dando forma a su alma, que ansía una inmortalidad imposible de ser expresada.

66 Victoria Cirlot, La visión abierta, Siruela, Madrid, 2010, p. 20.

67 "El temblor", de Mandorla (1982), en OC, t. 1, p. 416.

68 Relación observada, entre otros, por Peter Sloterdijk, Esferas, Siruela, Madrid, 2009. Léase al respecto el epígrafe titulado "La clausura en la madre" (pp. 251-270).

$69 O C$, t. 2, p. 1173.

70 "Y TODOS los poemas que he escrito...", de Fragmentos de un libro futuro (2000), en $O C$, t. 1, p. 580.

71 "ESTE tiempo vacío, blanco, extenso...", de Fragmentos de un libro futuro (2000), en $O C$, t. 1, p. 581. 
IMPLICACIÓN ESTÉTICO-RELIGIOSA DE LA OBRA DE ARTE

Concluimos nuestro trabajo contrastando el modo en que una aproximación sensorial al fenómeno artístico, tal y como hemos realizado con el estudio de la visión en la obra de José Ángel Valente, puede abrir paso hacia un estado de religiosidad. Según menciona Kosme de Barañano: "en la misma poesía de Valente hay una valoración del silencio: el silencio como la materia natural del texto y el poema como espacio del silencio; es decir, una conciencia paralela a la del escultor actual para quien la obra es el espacio del vacío, y el vacío la materia natural de la plástica"72. El poeta participa de una creación que surge del vacío, ámbito esquivo a una pesadez que posteriormente habrá de imponerse cuando se ascienda al mundo de la materia, de la representación, $\mathrm{y}$ trate de rechazarse cuando el verbo se asome hacia un nuevo vacío, comprendido ahora como sentido final de todo aquello que se ha ido desarrollando a lo largo de la creación. El arte, partiendo de este fundamento, une así dos vacíos, siendo su plasmación el modo por el que su esencia, de orden divino, se torna visible. Quedará así la realización proyectada y atraída a un mismo tiempo por una fuerza inexpresable en sí, pero expandida hacia y desde los contornos abismales del universo poético, marco de duelo entre el ángel y el creador.

Vista así, la realización estética llegará a reunir materia con forma, sustancia humana con sustancia divina, sin margen ya para el abismo abierto entre el sujeto y el objeto. Sin embargo, desde la concepción ortodoxa occidental, la divinidad se mantendrá separada de su creación, resultando de ello que, en función de unos moldes canónicos, el arte no logrará aunar satisfactoriamente realidad con ideal, pues queda un margen, una brecha abierta, entre el objeto artístico y el absoluto al que tenderá la palabra poética. En este caso, el vacío presentado a modo de Ursatz quedará supuestamente aunado con la manifestación, pero esta última quedará desligada estéticamente del fin o vacío ulterior.

Valente, como hemos ido señalando, participa de ambas concepciones una vez que su espíritu se encuentra más a gusto junto a una idea de divinidad inmanente a la esfera natural, proclive

72 Kosme de Barañano, Chillida, Heidegger, Husserl: el concepto de espacio en la filosofía y la plástica del siglo XX, Universidad del País Vasco, San Sebastián, 1992, p. 72. 
a buscar al dios en la materia, pese a que, paralelamente, se va a mostrar condicionado por la absorción de una cultura inclinada a hallar dicho absoluto en unas alturas metafísicas a las que el poeta, mediante el solo impulso estético, no logrará acceder al no contar con el apoyo de una religiosidad trascendental. Esta búsqueda espiritual, proyectada sobre ambas direcciones, externa e interna, o ascendente y descendente, no sólo resulta de evidencia exagerada en su obra, sino que, decididamente, constituye el motor de toda su creación. Por todo ello, el poeta trata de dotar de sentido, de hacer visible aun mediante su delimitación, esta nada hacia la que pretende irse abocando. Si nos acercamos a doctrinas alejadas, con vistas a este asunto, escuchamos de boca de François Cheng que:

el Hálito Yang encarna la potencia activa, y el Hálito Ying la dulzura receptiva; ambos necesitan el Hálito del Vacío medio -que, como su nombre indica, encarna el necesario espacio intermedio de encuentro y de circulación- para entrar en una interacción eficaz y, en la medida de lo posible, armoniosa ${ }^{73}$.

Cabría, entonces, equiparar un hálito extremo con el yo consciente, representado por la voluntad individual del artista, y otro, con el anima o naturaleza intuitiva del individuo. Esta unión se correspondería directamente con la comunión entre un sujeto incompleto y la atracción ejercida por el espíritu de la creación. Entre ambos se situaría la obra como plasmación de dicha búsqueda, como formación y, por lo tanto, como encarnación de una verdad que superará las intenciones del propio artista. A este respecto, vale seguir escuchando a Cheng, quien en referencia a esta formación alude a "una connivencia de alma a alma entre lo humano y lo divino... acuerdo nunca completo: siempre habrá una laguna que colmar. El infinito buscado es, efectivamente un in-finito" "74. Por todo ello, asistiremos a un vacío existente entre sujeto e infinito o, en el caso de José Ángel Valente, entre sujeto y Dios. No obstante, ya lo hemos mencionado, consideramos que este abismo quedará abierto, no en función de un orden estético, sino de uno puramente religioso, dado que la creación carece de un fondo seguro sobre el que caminar sin temor a caer, fondo sin el cual no resultará posible

73 F. Cheng, op. cit., p. 93.

74 Ibid., p. 102. 
acceder a una trascendente divinidad, dadas las limitaciones propias del verbo.

Por este mismo motivo, en una religiosidad inmanente al individuo con tendencia a desvelarnos una divinidad interior al ser, religiosidad propugnada desde enfoques, tanto antropológicos como psicológicos, el proceso de creación podrá manifestarse a modo de una serie de pulsiones proyectadas desde el anima, lo que desde esta exclusiva posición, obviamente, separará al creador y a su creación de un orden trascendente superior, de un Dios. Sin embargo, cabe suponer que el vacío que atraviesa el sujeto creativo con intención de acercarse a su objeto de búsqueda -el vacío que rodea la creación-, no tiene por qué mostrar una naturaleza diferente en su plano inferior y en aquel otro superior, pues ambos pertenecen a una dimensión metafísica, por lo que consideramos que la atracción del vacío o es doblemente ejercida desde ambos espacios extremos, pudiendo, por tanto, ser incluso la misma, o no es en absoluto, no animando la creación, en consecuencia, según esta segunda posibilidad, ningún espíritu divino.

En relación con esta cuestión, podemos observar que, a la hora de ofrecer una explicación del acto creativo, se suele acudir, de acuerdo con Jung, a la indagación en una dimensión profunda e inferior del ser, según la propuesta material que nos transmite Valente, o, en otros casos, tal y como nos presenta Platón ${ }^{75}$, a una dimensión elevada, trascendente e inalcanzable. Quedará, sin embargo, como corolario de lo presentado, la creencia en una misma divinidad que vivifica la creación en unos niveles y en otros, toda vez que existen motivos para creer que, de haber unión con la divinidad por un extremo, debe haberla también por el opuesto; de haber un Dios que precede a la creación, deberá resultar convergente con el Dios que la sucede. Paralelamente, puede decirse que de no haber lazo con la divinidad ya en un plano subconsciente ya en otro supraconsciente, nada habrá, quedando la creación como delirio evanescente del hombre jugando a ser Dios. Lo que nos resulta interesante de

${ }^{75}$ Lejos de acudir a un sustrato profundo, a un plano subterráneo desde donde mana la fuerza creadora, Platón sitúa el origen de ésta en una dimensión elevada, divina, situada sobre el individuo, con el que queda reunido mediante la "piedra heraclea". Así, podemos leer en el Ion que "los poetas no son más que intérpretes de los dioses que están poseídos cada uno por la divinidad que los gobierna" (Platón, Ion. Timeo. Critias, Alianza, Madrid, 2004, p. 38). 
estas creencias, en todo caso, dado lo hipotético de lo expresado, no obedece, ni mucho menos, a una explicación racional o irracional, pero de hondos fundamentos psicológicos, sino a cuanto pueda ofrecer un orden espiritual, religioso, que dominará el universo estudiado. Aquello que une al hombre con la creación sobrepasa, ciertamente, toda explicación racional y salta el abismo abierto a nuestros pies mediante una convicción en todo momento presente. Por todo ello, la concatenación racional, el indagar en los diferentes estratos poéticos, resultará adecuada poéticamente para tener una comprensión plena del símbolo; sin embargo, lo reiteramos, la unión con la divinidad, de llevarse a cabo, trascenderá por completo el fenómeno estético para asentarse en el religioso.

Por otra parte, la reunión con un dios no partícipe del espíritu de omnipotencia no deja satisfechas las ansias de absoluto del individuo, que emprenderá, en último término, una búsqueda metafísica, tal y como presenciamos de modo salpicado en la poesía del gallego, inclinación que se observa, por ejemplo, en el siguiente canto de Fragmentos de un libro futuro:

SI HAY un momento en el mundo

donde el pico de un pájaro

dijérase parece suspender el caos,

un súbito momento de tenue paz, ahora,

en el parque de una ciudad extraña donde me encuentro por

[azar.

Si existe repentino este silencio

en el leve descenso de la tarde,

si hay aves que se funden y hacen uno el canto y la quietud

y una mujer joven que cruza con su hijo pequeño de la mano

me mira, intensamente,

si este eterno es verdad, merecería

la pena haber venido,

estar presente, dios, en esta cita tuya no anunciada ${ }^{76}$.

Este anhelo de Dios -pese al correspondiente escepticismo notado- puede comprenderse como solución única y extrema a unas búsquedas radicales, puesto que, por mucho que uno bucee en diferentes niveles de la creación, lo que aliviará y colmará realmente los deseos del individuo de infinito será la exis-

76 "SI HAY un momento en el mundo...", de Fragmentos de un libro futuro (2000), en $O C$, t. 1, pp. 550-551. 
tencia de un Dios, comprendido de modo no inmanente al yo o al alma, sino entendido como el Otro, situado no dentro del ser o coincidente con la materia, sino por encima de ambos. De este modo, el encuentro con la divinidad no podrá llegar mediante una indagación estética, sino únicamente como consecuencia de una convicción que preceda a ésta. Por ello, para discernir la mística afirmativa de aquella otra escéptica, podemos decir que, cuando el místico represente estéticamente su encuentro con Dios, lo hará precedido de una convicción plena en lo real del objeto buscado, pues partirá de la fe. Por el contrario, en aquellos casos en que se busque la divinidad dentro de un plano estético, partiendo desde la duda, puesto que este fenómeno estético no podrá acercar lo que de antemano no se posee, únicamente se conseguirá prolongar más la agónica búsqueda, desarrollando en exceso una incredulidad permanente en la medida en que eso que se transforma a lo largo de ese recorrido no es la esencia, sino simplemente la apariencia. Por todo ello, el espíritu con que nazca la obra, concluimos, será todo lo que dote de uno u otro sentido a la creación, quedando ésta determinada por dicha convicción interna y no al revés.

Valente concibe el arte como expresión o concentración de lo inefable divino, sin que entremos a valorar qué es propiamente lo divino. La creación, qué duda cabe, es un acto del espíritu y, por ello mismo, posee cualidades sagradas. Pese a ello, no cabe duda de que si bien basta con la materialidad de la obra para satisfacer un anhelo divino de naturaleza panteísta o materialista -ya que incluso un defensor de la religión cristiana, como es el caso de Maragall, puede encontrar en ella satisfacción plena-, la necesidad de trascendencia de una obra denotará un anhelo de hallar una deidad separada de la creación, toda vez que cuanto se desee consistirá en la inencontrable alteridad. Cuando esto ocurre, cuando el arte requiere de la reducción exagerada del fenómeno estético a su ser más diáfano y elemental, se abandona el terreno existencial para entrar en uno esencial. "La acotación de un espacio insólito para el objeto carga a éste de aura, es decir, lo despoja de su instrumentalidad, de sus condicionamientos utilitarios" ${ }^{\prime 7}$, menciona nuestro poeta en referencia a este aspecto. Este modo de hacer y de comprender la actividad creativa nos acerca a una corriente estética que tiende a la expresión

77 OC, t. 2, pp. 552. 
de lo mínimo -concreción ${ }^{78}$-, manifestando así una inclinación a mostrar breves acotaciones de la línea completa del espíritu. Estas propuestas minimalistas reducen la obra a su expresión esencial, privándola de adornos, una vez que éstos son comprendidos como elementos superfluos y partícipes de un punto de vista condicionado y unívoco, planteamiento contrario al deseado por la expresión de una forma pura y abstracta propia de un plano esencial y transparente. La creación, en este caso, ganará en rigor y apertura y perderá en maleabilidad y en belleza plástica, estética ${ }^{79}$.

Concluimos nuestro estudio indicando que el encuentro de la materia con el espíritu necesita, como hemos ido viendo, del silencio, del vacío, para lograr su adecuada manifestación; de esta manera, la obra queda dotada de límites y, por lo tanto, de ritmos creadores, y, al mismo tiempo, queda provista de un necesario punto de fuga por donde no huirá, sino a través del cual se canalizará el espíritu. La obra se podrá comprender entonces como manifestación de lo sagrado, en ningún caso como expresión individual del artista, cuya primera función será ofrecerse, ofrecer su creación, para que se manifieste en ella lo divino.

Guillermo Aguirre Martínez Universidad Complutense de Madrid

78 "Quero recordar a fórmula Less is more, de Mies van der Rohe. Tamén nese senso tería que referirme á «Ley da adición negativa», formulada por Kandinsky, segundo o cal dous menos un acostuma a ser mayor que dous máis un. Tamén para Kandinsky, o punto que é igual a cero evoca a concisión absoluta, é decir, a máis grande contención que, sen embargo, fala. O punto é, segundo Kandinsky, a derradeira e única unión do silencio e a palabra... No seu caso, concentración significa extensión. Dicir o máximo de ideas no mínimo de palabras" (Xosé Luís García Canido, "Entrevista a José Ángel Valente", Microfisuras, 2001, núm. 13, pp. 75-76).

79 Manuel Fernández Casanova, a la hora de hacer referencia a esta particularidad propia de la creación de Valente, indica que "nos enfrentamos a un tipo de obra abierta, en la medida en que, más que originarse en la disposición de un yo fuerte, surge como consecuencia de una maniobra de desbordamiento de la conciencia del autor, encarada hacia la consecución de un estado de percepción máxima, lo que posibilita una iluminación de la realidad superior y convierte el acto inventor en acto de conocimiento" ("Cuatro referentes para una poética de la retracción y del límite”, en Pájaros raíces. En torno a José Ángel Valente, eds. M. Agudo y J. Doce, Abada, Madrid, 2010, p. 278). 